\title{
Connexin Channel-Dependent Signaling Pathways in Inflammation
}

\author{
K.E. Ludwig Scheckenbach ${ }^{a}$ Sophie Crespin ${ }^{a}$ Brenda R. Kwak ${ }^{\text {b, c }}$ \\ Marc Chanson ${ }^{a}$ \\ Departments of a Pediatrics, ${ }^{b}$ Pathology and Immunology, and ${ }^{C}$ Internal Medicine-Cardiology, Geneva University \\ Hospitals and University of Geneva, Geneva, Switzerland
}

\section{Key Words}

Acute lung injury $\cdot$ Atherosclerosis $\cdot$ Cerebral

inflammation $\cdot$ Connexin $\cdot$ Gap junctions

\begin{abstract}
Inflammation is a highly regulated process with common but also specific characteristics in each tissue affected. Recruitment of leukocytes from the blood to the injured tissue is an important early step in the inflammatory cascade. This review highlights the role of connexins (Cxs) in the regulation of both acute and chronic inflammatory processes. Cxs form gap junction channels that provide a cytoplasmic continuity between adjacent cells allowing the intercellular exchange of ions and metabolites. Their structural halves form connexons or hemichannels. Each of them consists of $6 \mathrm{Cx}$ proteins and hemichannels not taking part in gap junction formation but facilitating the release of small molecules such as ATP. Based on the differential distribution of various Cxs in different tissues such as the brain, lung capillaries and large blood vessels, our aim was to analyze the specific roles of Cxs in the inflammatory process in these tissues. Three typical sites of inflammation were chosen to shed light on similarities and differences in several types of responses:
\end{abstract}

(1) atherosclerosis as a model for chronic inflammation, (2) the lung as an example of acute inflammation and (3) the 'immune-privileged' environment of the brain to highlight specific reactions of the vasculature to ischemic damage and inflammation at this site.

Copyright $\odot 2010$ S. Karger AG, Basel

Previous articles in this special topic series: 1. Pohl U, Meininger G: Editorial. J Vasc Res 2009;45:503. 2. Hudlicka O, Brown MD: Adaptation of skeletal muscle microvasculature to increased or decreased blood flow: role of shear stress, nitric oxide and vascular endothelial growth factor. J Vasc Res 2009;46:504-512. 3. Krenzt AJ, Clough G, Byrne CD: Vascular disease in the metabolic syndrome: do we need to target the microcirculation to treat large vessel disease? J Vasc Res 2009;46:515-526. 4. Sen CK, Gordillo GM, Khanna S, Roy S: Micromanaging vascular biology: tiny microRNAs play big band. J Vasc Res 2009;46:527-540. 5. Orr AW, Hastings NE, Blackman BR, Wamhoff BR: Complex regulation and function of the inflammatory smooth muscle cell phenotype in atherosclerosis. J Vasc Res 2010;47:168-180. 6. Van den Akker J, Schoorl MJC, Bakker ENTP, vanBavel E: Small artery remodeling: current concepts and questions. J Vasc Res 2010;47:183-202.

\section{KARGER}

Fax +41613061234 E-Mail karger@karger.ch www.karger.com
(C) 2010 S. Karger AG, Basel

$1018-1172 / 11 / 0482-0091 \$ 38.00 / 0$

Accessible online at:

www.karger.com/jvr
Dr. Marc Chanson

Laboratory of Clinical Investigation III

HUG-PO Box 14, 4, Gabrielle-Perret-Gentil

CH-1211 Geneva (Switzerland)

Tel. +41 22372 4611, Fax +4122372 4088, E-Mail Marc.Chanson@ @cuge.ch 


\section{Introduction}

Inflammatory reactions are involved in multiple pathologic conditions including acute and chronic diseases. Inflammation encompasses a multistep process that is characterized by the release of cytokines, chemokines and growth factors, and by the transmigration of inflammatory cells, such as neutrophils, monocytes and lymphocytes, from the blood to the affected tissue. This process comprises a high level of coordination requiring effective means of intercellular communication. Gap junctions form transmembrane channels providing for direct cytoplasmic continuity between adjacent cells and thus direct intercellular exchange of information, a process referred to as gap junctional intercellular communication (GJIC) [1].

Gap junction channels are made by the docking of two halves, each half being located at the membrane of each cell in contact. They consist of hexamers of connexin (Cx) proteins, a structure referred to as connexons or hemichannels, which by themselves may provide a means for transplasmalemmal communication [2,3]. Ions and molecules up to $1 \mathrm{kDa}$ can pass through $\mathrm{Cx}$ aqueous pores of a diameter of $2 \mathrm{~nm}$. Numerous endogenous metabolites such as cyclic AMP (cAMP), inositol 1,4,5-triphosphate $\left(\mathrm{IP}_{3}\right)$ or glutamate have been shown to permeate gap junction channels $[1,2,4,5]$. Cx proteins form a family of about 20 members and the properties of intercellular transmission of molecules through gap junction channels depend on their composition $[1-3,6]$. Most tissues express more than one $\mathrm{Cx}$ and tissue homeostasis depends not only on intercellular communication but also on the specific pattern of $\mathrm{Cx}$ expression. Cxs are dynamic proteins with half-lives between 1 and $5 \mathrm{~h}$, indicating that gap junction channels are fully exchanged several times per day [7]. This may provide a means to regulate direct cytoplasmic interaction between cells in normal conditions and to adapt intercellular signaling in various states of diseases. Indeed, Cx expression and distribution can change dramatically in pathologic conditions such as inflammation $[8,9]$. Increasing evidence also hints at important roles of $\mathrm{Cx}$ hemichannels (connexons) in tissue homeostasis and in the pathophysiology of numerous diseases.

This review concentrates on the role of $\mathrm{Cx}$ channels (gap junctions and connexons) at the cross talk between leukocytes, the vasculature and injured tissue during progression of inflammation. Atherosclerosis has been chosen to elucidate the role of $\mathrm{Cx}$ channels in the regulation of chronic inflammation in the large vasculature. A closer look at the lungs allows us to characterize the func- tion of Cx channels within the capillary bed during acute inflammation of the organ. Finally, we will address glutamate excitotoxicity and inflammation in the brain. This phenomenon typically appearing after ischemia and hemorrhage will give us the possibility to define specific signaling pathways between the brain vasculature, microglia and astrocytes.

\section{Role of Cx Channels in the Pathogenesis of Atherosclerosis}

Vascular function is orchestrated by a precisely balanced regulatory system. This implies not only the wellknown regulation of the vascular tone by molecules secreted by endothelial cells (ECs) such as nitric oxide or prostaglandins, but also an optimally operating instrument of radial and longitudinal cell-to-cell communication. Cx channels provide such a way of intercellular communication [10-13]. They form not only homocellular gap junctions between adjacent smooth muscle cells (SMCs) or between neighboring ECs but also heterocellular gap junctions between ECs and SMCs. Indeed, electrical intercellular communication has been proven the basis of different types of vascular responses [14-16], including the rapid arteriolar conducted response. Consequently, modulation of electrical communication between vascular cells by inflammatory mediators might affect vascular function. Cx37, Cx40, Cx43 and Cx45 are expressed in the vascular wall, but their expression is not uniform throughout the vascular tree. In general, Cx37 and $\mathrm{Cx} 40$ are co-expressed in ECs, whereas $\mathrm{Cx} 43$ and $\mathrm{Cx} 45$ are present in SMCs. In addition, $\mathrm{Cx} 43$ has been observed in ECs of the microvasculature, and it is present in ECs at branch points of arteries that experience turbulent blood flow [17]. There is some evidence supporting the idea that GJIC can establish between leukocytes and ECs. Thus, transmigration of leukocytes across an EC monolayer is altered in the presence of $\mathrm{Cx}$-mimetic peptides or gap junction channel blockers [18-20]. However, establishment of heterocellular GJIC between leukocytes and EC (or epithelial cells) has not been observed in other laboratories [9, 21]. Additional studies in more physiological settings are needed to unambiguously address whether heterocellular GJICs are involved in leukocyte transmigration.

Atherosclerosis is a progressive disease characterized by the accumulation of macrophages, $\mathrm{T}$ lymphocytes, SMCs and lipids in the vascular wall in large- and medium-sized arteries. Inflammation is a central element at all 
stages of atherosclerosis and involves paracrine intercellular communication including cytokines, chemokines and growth factors [22-26]. A number of risk factors such as elevated low-density lipoprotein (LDL), obesity, free radicals, hypertension, diabetes and infectious microorganisms may cause the initiating step of atherosclerosis, i.e. endothelial dysfunction [27]. Endothelial dysfunction leads to the increase in cell adhesion molecules and secretion of chemo-attractants. Subsequently, monocytes migrate to the arterial intima where they mature into macrophages, ingest lipids and finally transform into macrophage foam cells. This fatty-steak-type of atherosclerotic lesion is later covered by SMCs that migrate from the media to the intima where they proliferate and secrete extracellular matrix components, which participate in the formation of a strong fibrous plaque. In the advanced atherosclerotic plaque, foam cells die and release lipids that form the necrotic core of the lesion. Later on, the fibrous cap may rupture and induce the formation of a thrombus at the site of the lesion, a process implicated in $60 \%$ of cases of sudden death caused by thrombosis [28]. The development of the atherosclerotic plaque in vivo, but also in in vitro exposure to atherosclerotic risk factors such as turbulent flow, hypertension and hypercholesterolemia, is correlated with changes in the pattern of vascular Cx expression [reviewed in ref. 13, 29]. Thus, Cx37 disappears from the endothelium covering the advanced atherosclerotic plaque and its expression is also decreased after several months of high-cholesterol diet in mice [30, 31]. Oxidation products of lipoprotein-derived phospholipids downregulate $\mathrm{Cx} 37$ in murine endothelium of carotid arteries and in cultured ECs [32]. Moreover, Cx37 can be found in blood monocytes, macrophages and macrophage foam cells in early and late atherosclerotic plaques as well as in SMCs beneath the advanced lesions [30,33]. Because all these cell types are key players in atherosclerosis, we expected a role for $\mathrm{Cx} 37$ in atherogenesis.

The role of $\mathrm{Cx} 37$ in atherosclerosis was investigated in apolipoprotein E-deficient $\left(\mathrm{ApoE}^{-/-}\right)$mice, a mouse model for the disease. $\mathrm{C} \times 37^{-/-} \mathrm{ApoE}^{-/-}$mice developed more aortic lesions than $\mathrm{Cx} 37^{+/+} \mathrm{ApoE}^{-/-}$mice [33]. By in vivo adoptive transfer, we showed enhanced monocyte and macrophage recruitment to the atherosclerotic lesions that was caused by elimination of $\mathrm{Cx} 37$ in these leukocytes but not in the endothelium. ATP can diffuse through various types of gap junctions and $\mathrm{Cx}$ hemichannels, including those made of $\mathrm{Cx} 37$ [4, 34, 35]. Interestingly, active Cx37 hemichannels inhibited leukocyte adhesion in primary monocytes, macrophages and a macrophage cell line (H36.12j). Moreover, this anti-adhe- sive effect was mediated by ATP release into the extracellular space [33]. Thus, Cx37 hemichannels may control the initiation of atherosclerotic plaque development by regulating monocyte adhesion by a mechanism that remains to be further investigated.

As mentioned before, the expression pattern of $\mathrm{Cx} 37$ shows not only specific changes during early atherosclerotic lesion development but also in late atherosclerosis. To obtain more insight into the molecular role of $\mathrm{Cx} 37$ in advanced atherosclerosis, micro-array analysis was used for gene expression profiling in aortas of $\mathrm{Cx} 37^{+/+} \mathrm{ApoE}^{-/-}$ and $\mathrm{Cx} 37^{-/-} \mathrm{ApoE}^{-/-}$mice before and after 18 weeks of a cholesterol-rich diet [36]. Out of $>15,000$ genes, 106 genes were significantly differentially expressed in young mice before the diet; differences mostly involved genes in cellto-cell signaling and interaction, cellular compromise and nutritional disease pathways. In addition, in advanced atherosclerotic lesions, important changes were found in genes and proteins involved in vascular calcification and matrix degradation. Thus, Cx37 deficiency alters global differential gene expression profiles in young mice towards a pro-inflammatory phenotype, which is then further influenced in advanced atherosclerosis with possible effects on plaque stability.

Cx40 is also implicated in atherosclerotic plaque formation. Its function and expression is influenced by factors such as oxidative stress, prothrombotic molecules, pro-inflammatory cytokines and classic cardiovascular risk factors [37]. Cx40 is expressed in ECs of healthy blood vessels and it disappears from the endothelium covering advanced atherosclerotic lesions [30]. Interestingly, aging seems to induce a general decrease in endothelial Cx expression while only $\mathrm{Cx} 40$ remains relatively undisturbed for a long time (up to 20 months of age in rats) [38]. As this Cx takes part in the longitudinal transmission of endothelium-dependent vasodilator responses and is involved in the signal transmission between afferent arterioles and renin-secreting cells of the renal juxtaglomerular apparatus [39-41], mice deficient in the $\mathrm{Cx} 40$ gene are hypertensive. Moreover, a polymorphism of Cx40 has been linked to an increased risk of hypertension [42]. Because hypertension is a well-known risk factor of atherosclerosis, in vivo studies of atherosclerosis in Cx40-deficient mice would be irrelevant. Therefore, atherosclerosis-susceptible mice with endothelial deletion of $\mathrm{Cx} 40$ were created using a CreLoxP approach. These mice were indeed not hypertensive and had a normal heart rate [43]. Young mice with endothelial deletion of $\mathrm{Cx} 40$ developed spontaneous atherosclerotic lesions in the aortic sinus even without a high-cholesterol diet. In addition, the 
Control
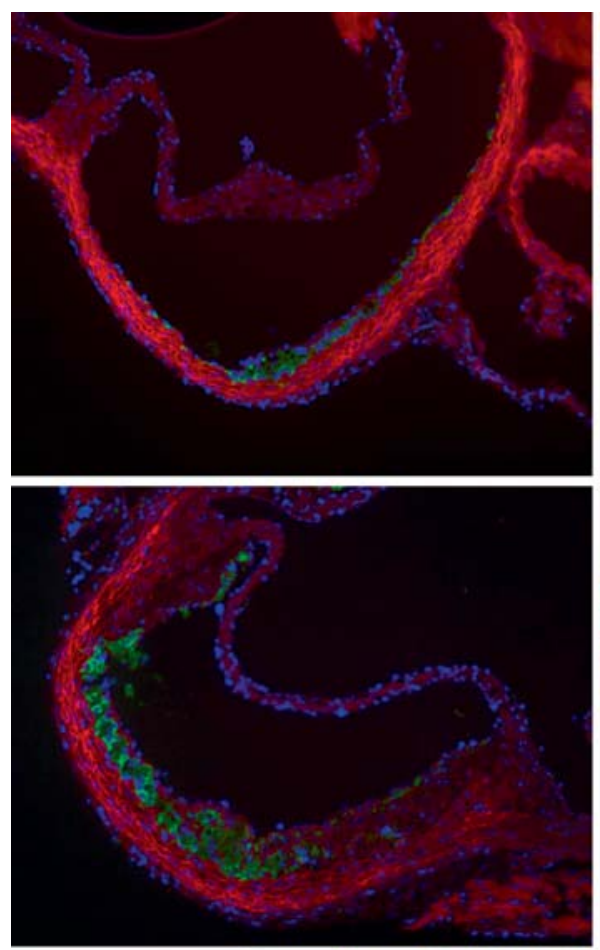

Fig. 1. Cryostat sections of aortic sinuses from control mice (left) and mice with endothelial-specific deletion of Cx40 (right). Macrophages were detected in aortic sinuses by CD68 immunostaining (green) after different periods of cholesterol-rich diet: no diet (a), and 5 (b) and 10 weeks of $\operatorname{diet}(\mathbf{c})$. Mice with endothelial-specific deletion of $\mathrm{Cx} 40$ show enhanced macrophage staining at these early stages of atherogenesis. Sections were counterstained with Evans blue (red) and DAPI (blue). Bar: 200 $\mu \mathrm{m}$.

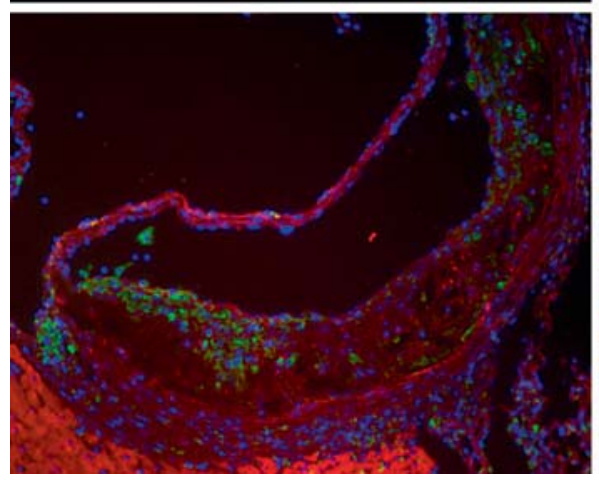

$\mathrm{C} \times 40$ deletion
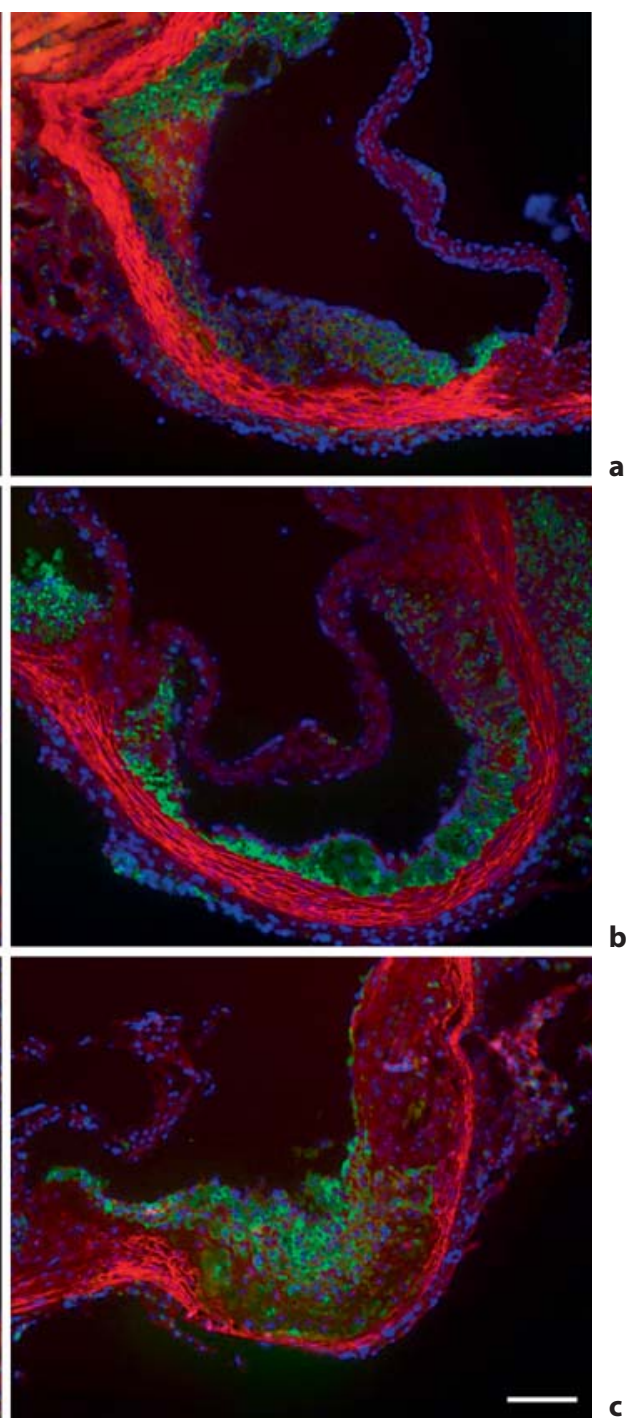

progression of atherosclerosis was increased after 5 or 10 weeks of a high-cholesterol diet, as illustrated by the prominent detection of macrophages in these lesions (fig. 1). Particularly in the early stage of atherosclerosis development, recruitment of blood monocytes depends on the expression of adhesion molecules, e.g. vascular cell adhesion molecule-1 (VCAM-1). Interestingly, VCAM-1 expression in ECs is increased in mice with endothelial deletion of Cx40. VCAM-1 expression is known to be regulated by the activity of the $5^{\prime}$-ecto-nucleotidase CD73 at the surface of ECs [44]. CD73 hydrolyzes extracellular nucleotides and liberates adenosine (ADO), which in turn triggers the intracellular generation of $\mathrm{CAMP}$ by $\mathrm{A}_{2} \mathrm{~B}$ receptor stimulation. CD73 is known to decrease leuko- cyte adhesion to the endothelium, and mice with CD73 deletion show constitutive vascular inflammation [4547]. Remarkably, mice with endothelial Cx40 deletion had decreased expression of CD73 in en face staining of the aorta. Moreover, the use of the endothelial mouse bEnd. 3 cell line, which constitutively expresses CD73 and $\mathrm{Cx} 40$, revealed that targeting $\mathrm{Cx} 40$ by an antisense strategy increased monocyte adhesion to a monolayer of ECs [43]. These in vitro experiments directly indicated that deletion of endothelial Cx40 leads to increased adhesion of leukocytes to ECs, thus explaining the protective role of endothelial Cx40 in atherogenesis.

In contrast to the athero-protective role of $\mathrm{Cx} 37$ and Cx40, Cx43 appears atherogenic. In human coronary 


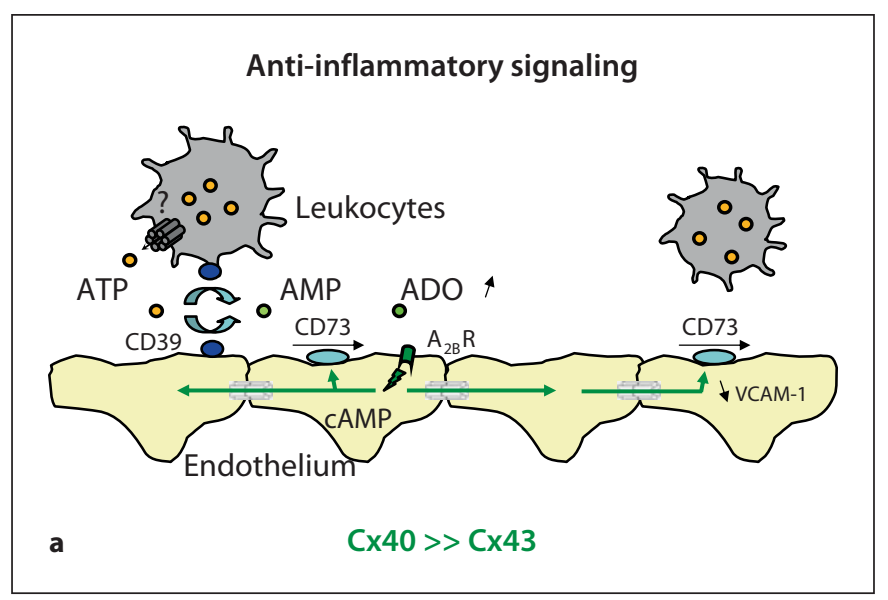

Fig. 2. Hypothetical mechanism of $\mathrm{Cx}$-mediated regulation of leukocyte adhesion to the endothelium. Circulating leukocytes may release ATP via hemichannels made of $\mathrm{Cx} 37$ (in monocytes) or $\mathrm{Cx} 43$ (in neutrophils), although the expression of the latter $\mathrm{Cx}$ remains controversial. ATP is converted to ADO by successive activity of CD39 (located at the surface of leukocytes and ECs) and CD73 (located at the surface of ECs). a The conversion rate favors the production of ADO, which activates ADO receptors $\left(\mathrm{A}_{2 \mathrm{~B}} \mathrm{R}\right)$ on the endothelium. $\mathrm{A}_{2 \mathrm{~B}} \mathrm{R}$ triggers cAMP-dependent signaling, which further activates CD73, and maintains the expression of endothelial adhesion molecules for leukocytes (such as VCAM-1) to very low levels. $\mathrm{A}_{2 \mathrm{~B}} \mathrm{R}$ engagement also enhances Cx40-mediated GJIC, enabling the propagation of anti-adhesion

atherosclerosis, $\mathrm{Cx} 43$ expression in intimal SMCs is increased at early stages of the disease but reduced in advanced atheroma [48]. Hypercholesteremia-induced atherosclerosis in rabbits resulted in $\mathrm{Cx} 43$ expression associated with macrophage foam cells and, comparable with human atherosclerosis, reduced levels of $\mathrm{Cx} 43$ between intimal SMCs were observed in advanced lesions in the rabbit [49]. Similar temporal expression patterns of Cx43 in intimal SMCs and macrophage foam cells were observed during atherogenesis in LDL receptor-deficient mice $\left(\mathrm{LDLR}^{-I-}\right)$ fed a high-cholesterol diet for 0 , 6,10 or 14 weeks [30]. In these mice, $\mathrm{Cx} 43$ was expressed in the endothelium at the shoulder region of advanced atherosclerotic plaques, where disturbed hemodynamic forces have been established. The role of $\mathrm{Cx} 43$ in atherogenesis was examined in $\mathrm{LDLR}^{-/-}$mice with normal $\left(\mathrm{C} \times 43^{+/+}\right)$or reduced $\left(\mathrm{Cx} 43^{+/-}\right)$levels of $\mathrm{Cx} 43$ fed a cholesterol-rich diet for 14 weeks. Progression of atherosclerosis was reduced by $50 \%$ in the thoracic-abdominal aorta and in the aortic sinuses of $\mathrm{Cx} 43^{+/-} \mathrm{LDLR}^{-/-}$mice compared to $\mathrm{Cx} 43^{+/+} \mathrm{LDLR}^{-/}$controls. The composition of the atherosclerotic plaques in $\mathrm{Cx} 43^{+/-} \mathrm{LDLR}^{-/-}$mice

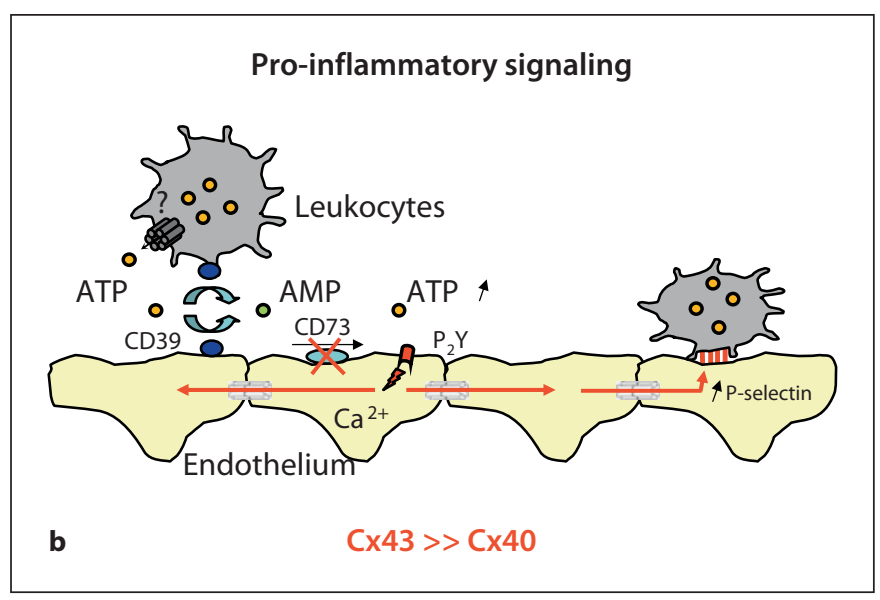

signaling between ECs. This prevents leukocyte adhesion along the endothelium, thus providing an anti-inflammatory mechanism. The nature of the anti-inflammatory signal remains to be identified. b In the presence of a pro-inflammatory stimulus, the expression of $\mathrm{Cx} 40$ decreases while that of $\mathrm{Cx} 43$ increases. In the absence of Cx40, CD73 activity is decreased, thus reducing the use of ATP as substrate. ATP in turn activates purinergic receptors $\left(\mathrm{P}_{2} \mathrm{Y}\right)$ on ECs, which trigger $\mathrm{Ca}^{2+}$-dependent signaling. $\mathrm{Ca}^{2+}$-dependent signaling propagates through $\mathrm{Cx} 43$-made gap junction channels and increases the expression of endothelial adhesion molecules for leukocytes (e.g. P-selectin). This favors leukocyte adhesion, thus providing a pro-inflammatory mechanism.

was altered as well: they exhibited a smaller lipid core, a reduced amount of leukocytes, and a thicker fibrous cap containing more SMCs and collagen [50]. The plaques were globally more stable in $\mathrm{Cx} 43$ heterozygous mice than in homozygous controls. Thus, reducing $\mathrm{Cx} 43 \mathrm{ex}-$ pression in mice provides beneficial effects on both the progression and composition of atherosclerotic lesions $[50,51]$.

After initial investigations regarding altered Cx expression in diseased vessels of animals or humans, the availability of $\mathrm{Cx}$-deficient mice has helped us to recognize the modulatory roles of these proteins in atherosclerotic disease. Thus, Cx40 appeared critical for a healthy endothelium (fig. 2). Loss of $\mathrm{Cx} 40$ promotes endothelial dysfunction, the initiating step of the disease. Cx37 has a protective role in early atherosclerosis by controlling ATP-dependent monocyte adhesion. In addition, Cx37 may play a role in the stability of the advanced atherosclerotic lesion. $\mathrm{Cx} 43$ is not only expressed in most atheromaassociated cells, it also seems to exhibit multiple, and mostly atherogenic roles throughout development of the disease. 


\section{Role of Cx Channels in Normal and Inflamed Lungs}

The lung tissue is not only the place of gas exchange, it also takes a frontline position in the defense against pathogens from the environment. The lung has been endowed with effective means to fulfill these requirements. They include the coordinated ciliary movement of tracheal, bronchial and bronchiolar airway epithelial cells, the adequate production of fluid at the airway epithelium surface and of surfactant in the alveoli. In order to integrate these different functional means, a high degree of intercellular coordination is required. Cx-made channels, both in the form of hemichannels and gap junctions, have been shown to contribute importantly to the regulation of tissue homeostasis and host defense. Each cell type in the lung expresses a distinct pattern of Cxs. The composition of this pattern influences tissue function but it does change with inflammation [reviewed in ref. 52-54]. In this section, we will review recent findings on the role of $\mathrm{Cx}$ channels in fine-tuning the balance between proand anti-inflammatory signaling pathways in the lung.

In epithelial cells, the intercellular propagation of calcium waves between airway, pulmonary type I and pulmonary type II cells have been involved in coordinated ciliary beating [55-57], inflammatory cytokine production [58], surfactant production and host defense [59-64]. Two mechanisms of propagation, which are not mutually exclusive, have been proposed. One includes the transmission of $\mathrm{IP}_{3}$ from one cell to another via gap junction channels [56, 57, 61, 62, 65]. A second mechanism involves functional connexons that release ATP to the extracellular space, which in turn stimulates purinergic receptors to mobilize intracellular calcium in surrounding cells $[61,63,65,66]$. Which pathway is predominant in this context is still a matter of debate [54]. Although Cx hemichannels may contribute to ATP release, recent data in airway epithelial cells indicate that this role may instead be fulfilled by pannexons, the membrane channels constituted by pannexin 1 [67]. Of note, airway cell lines and airway cells in primary cultures under non-differentiating conditions may express distinct $\mathrm{Cx}$ types $[53,68]$. Finally, impaired Cx channel expression/regulation may contribute to the abnormal immune response observed in pulmonary diseases like cystic fibrosis $[58,69-72]$. At last, loss of Cx37 expression in mouse bronchiolar airway epithelial cells has been associated with allergic airway disease and Th2 cytokine production [73].

Cx43-mediated calcium signaling in lung tissue is thought to be important in the pathophysiology of acute inflammatory responses of the organ, particularly in pa- thologies such as acute lung injury (ALI) and acute respiratory distress syndrome, which are attributable to severe lung inflammation in sepsis, infection, acid aspiration or head injury [74]. ALI and acute respiratory distress are characterized by massive invasion of cells and formation of protein-rich edema fluid in the interstitial and intraalveolar spaces, which leads to impaired gas exchange and increased pulmonary resistance. These alterations result in opacities on X-rays of the lung tissue, which develop rapidly over the entire lung, thus reflecting the rapid spread of inflammation [75]. Interestingly, imaging of the intact perfused lung showed evidence of calcium waves that propagate along pulmonary vessels $[76,77]$. Lung ECs have been shown to express Cx37, Cx40 and $\mathrm{Cx} 43$ [53, 54]. Endothelial deletion of $\mathrm{Cx} 43$ in mouse models abolished calcium wave propagation, suggesting a major contribution of $\mathrm{Cx} 43$ in this process [77]. These calcium waves were generated from a distinct subset of pacemaker ECs that are localized at the pulmonary branch points and that are particularly sensitive to mechanical stress [76].

Cx43-dependent calcium signaling between alveolar ECs has been proposed to provide a pro-inflammatory signaling mechanism contributing to the spatial expansion of inflammation. In this context, calcium waves were shown to promote exocytosis of P-selectin in postcapillary venules [77], thereby promoting leukocyte rolling to the vascular surface. Consistent with this finding, depression of $\mathrm{Cx} 43$-mediated GJIC using specific blocking peptides in mouse pneumocyte and EC lines was associated with a marked reduction in neutrophil adhesion mostly to the EC surface [78]. The pro-inflammatory role of $\mathrm{Cx} 43$ was confirmed in vivo using $\mathrm{Cx} 43^{+/-}$mice with reduced $\mathrm{Cx}$ expression in the lung. These mice showed an almost 50\% decrease in neutrophil recruitment to the alveolar space $24 \mathrm{~h}$ after lung inflammation evoked by intratracheal instillation of Pseudomonas aeruginosa lipopolysaccharide (LPS) [78]. Finally, the intratracheal instillation of Cx43-blocking peptides efficiently reduced neutrophil recruitment after LPS treatment [78]. Conversely, mice expressing a truncated form of Cx43 (known to enhance the Cx channel function [79, 80]) exhibited increased neutrophil recruitment in response to LPS instillation [78]. Although these results indicate that $\mathrm{Cx} 43$-dependent spread of calcium waves between ECs serves as a pro-inflammatory mechanism during lung inflammation by promoting adhesion of leukocytes to the endothelium, the nature of $\mathrm{Cx} 43$ signaling (through connexons and/or gap junctions) remains to be determined. Opening of connexons during 
acute cellular stress may also challenge cell fate (necrosis or apoptosis), therefore influencing the course and severity of inflammation [81].

In contrast to $\mathrm{Cx} 43$, the expression of $\mathrm{Cx} 40$ decreased in the lung of mouse and rabbit models of ALI. This phenotype was associated with an overload of intracellular calcium in ECs, possibly because of interruption of calcium wave propagation $[82,83]$. In another study, mice with endothelial-specific deletion of $\mathrm{Cx} 40$ showed increased transmigration of neutrophils from the blood to the alveolar space early (3-6 h) after intratracheal instillation of LPS [43]. These results are indicative of a protective role of $\mathrm{Cx} 40$ in the process of leukocyte recruitment. Interestingly, lung microvessels of mice with endothelialdeletion of $\mathrm{Cx} 40$ showed decreased expression of CD73, the ectoenzyme that hydrolyzes extracellular nucleotides to liberate ADO. Extracellular nucleotides are liberated during hypoxia or inflammation by several potential mechanisms, including exocytosis of ATP-containing vesicles or transport via hemichannels/pannexons, nucleoside transporters and ATP-binding cassette transporters [84]. There is a large body of evidence indicating that CD73 protects against ALI by preventing leukocyte adhesion to the endothelium via intracellular cAMP signaling triggered after stimulation of $\mathrm{A}_{2} \mathrm{~B}$ receptors by $\mathrm{ADO}$ [85-87]. In the mouse endothelial bEnd.3 cell line, targeting $\mathrm{Cx} 40$ using a siRNA strategy decreased the expression and activity of CD73. This decrease in CD73 activity was associated with enhanced adhesion of neutrophils to the EC monolayer [43]. Moreover, it was shown that $\mathrm{Cx} 40$-made intercellular channels can convey antiadhesion signals for leukocytes between ECs following activation of ADO receptors. Thus, Cx40 contributes to anti-inflammatory signaling pathways in the lung by preventing neutrophil adhesion to the endothelium.

Of note, the opposite regulation of $\mathrm{Cx} 40$ and $\mathrm{Cx} 43 \mathrm{oc}$ curs during the course of an inflammatory response in the lung $[78,82,83,88]$. Whereas a high ratio for $\mathrm{Cx} 40$ $(\mathrm{Cx} 40>\mathrm{Cx} 43)$ delays the adhesion of neutrophils to ECs, a high ratio for $\mathrm{Cx} 43(\mathrm{Cx} 43>\mathrm{Cx} 40)$ promotes their transmigration across the endothelial barrier (fig. 2). Cxs may also provide a bridge between inflammatory circulating cells and inflamed tissue cells. Although their expression in neutrophils is controversial $[21,89]$, it was recently reported that these leukocytes may release ATP via hemichannels made of $\mathrm{Cx} 43$ [90]. In conclusion, $\mathrm{Cx} 43-$ and Cx40-made channels with their specificity in propagating pro- or anti-inflammatory signals appear as key modulators of acute lung inflammation.

Connexins in Inflammation

\section{Role of Cx Channels in Cerebral Tissue Homeostasis and Inflammatory Responses}

The brain is a highly differentiated, heterogeneous organ with distinct demands on the supplying vascular system. Though it accounts for only $2 \%$ of the body weight, it receives $\sim 15 \%$ of the cardiac output [91]. Since neurons, as well as other cell types such as oligodendrocytes, are particularly vulnerable and have a poor capacity to regenerate, brain tissue demands a continuous vascular supply of oxygen and glucose in order to maintain its structural and functional integrity [92]. Moreover, due to the heterogeneity of the tissue, energy needs are unequal and change constantly in different brain regions and as a function of its state of activity. In order to match oxygen and glucose delivery through blood flow with the local metabolic demands, the cerebral circulation is endowed with various control mechanisms comprising [93]: (1) a cerebrovascular autoregulation, which prevents harmful fluctuations in cerebral blood flow that result from changes in systemic arterial pressure; (2) a functional hyperemia, matching the delivery of blood flow according to the activity level of each brain region, and (3) a bloodbrain barrier (BBB) that impedes influx of most compounds from blood to brain and regulates the transfer of nutrients. These regulatory processes require a high degree of cellular communication which may be provided in part by $\mathrm{Cx}$-made channels. In this section, we review the distinct roles of $\mathrm{Cx}$-mediated communication in the context of cerebrovascular autoregulation and in the $\mathrm{BBB}$ in order to define the possible roles of $\mathrm{Cx}$-mediated signaling in pathophysiological events such as the inflammatory reaction after hypoxic-ischemic insults [94-96].

The vascular supply of the brain is provided by four large arteries, the carotid and the vertebral arteries, which merge to form the circle of Willis at the base of the brain [92]. The arteries arising from the circle of Willis travel along the brain surface, giving rise to arteries penetrating the brain parenchyma. Due to this special anatomic organization, two thirds of vascular resistance - and consequently the control of the parenchymal blood flow of the brain - are located outside the organ itself [97]. Cx43 and $\mathrm{Cx} 40$ have been shown to be expressed in SMCs and ECs of these extracerebral vessels [98], suggesting a role for GJIC in the regulation of blood flow by transmitting upstream signaling from the brain parenchyma [99]. The exchange of signals between brain parenchyma and penetrating vessels is highly controlled. With the exception of certain brain regions such as the neurohypophysis or the pineal gland, brain tissue is separated from blood ves- 
sels by the closely regulated BBB [96]. Several cell types contribute to this permeability barrier. First, a monolayer of non-fenestrated blood vessel ECs exhibit tight junctions and gap junctions made of $\mathrm{Cx} 43$ and $\mathrm{Cx} 40[96,100]$. Secondly, this monolayer of ECs is surrounded by astrocytes that express Cx43 and Cx30 [101]. Astrocyte foot processes are in close proximity to the EC monolayer and the basal lamina. Although astrocytes do not directly contribute to the barrier functions in mammalians, they play an important role in the interaction between blood and brain tissue [96]. Finally, other cellular contributors to the BBB are pericytes, which are found between ECs, astrocytes, macrophages and the basement membrane. Apart from small molecules such as $\mathrm{O}_{2}$ or $\mathrm{CO}_{2}$ that have the capacity to pass the $\mathrm{BBB}$ along their concentration gradient without specific transport mechanisms [102], larger molecules need special gateways. Most essential nutrients such as glucose and amino acids, but also other molecules such as insulin, leptin or iron transferrin belong to this group [103-105]. Thus, the BBB provides a natural defense against toxic and infective agents circulating in the blood and helps to maintain the chemical composition of the interstitial fluid which is required for normal functioning of the central nervous system (CNS).

The morphological and phenotypical characteristics of astrocytes are tailored to provide optimal support for synaptic transmission. Fine perisynaptic processes cover most of the synapses, but their large-diameter vascular processes, named endfeet, are closely apposed to the vessel wall and $>99 \%$ of the intracerebral vascular surface are covered by astrocytic endfeet [106]. Interestingly, $\mathrm{Cx} 43$ expression is concentrated in the endfeets of astrocytes, surrounding both the EC layer of blood vessels and the synapses of neurons [106]. Taking into consideration that astrocytes cover defined non-overlapping spatial domains within which they envelop entire segments of arterioles, this distribution of $\mathrm{Cx} 43$ enables astrocytes to serve as a means of transmission of signaling molecules or metabolites from the endothelium to neurons and vice versa. By interastrocytic GJIC, this special control can be extended over a larger area, involving multiple astrocytic domains. Indeed, intercellular trafficking of glucose and its metabolites (including lactate) has been detected through gap junctions made of $\mathrm{Cx} 30$ and $\mathrm{Cx} 43$ using radio-labeled compounds or fluorescent glucose compounds [107]. The intercellular trafficking of such molecules involves a high degree of both neuronal and vascular regulation. Neuronal glutamatergic synaptic activity regulates the gap-junctional transfer of glucose. The gap junction-coupled astrocytic network sustains thus the delivery of glucose or lactate and finally glutamatergic synaptic transmission of neurons [108]. From the vascular point of view, vasoactive molecules such as endothelins have been shown to block glucose trafficking via gap junctions and to increase astrocytic glucose uptake and proliferation $[107,109]$.

Inversely, the astrocytic network has been proposed to be the cellular correlate of communication from neurons to intracerebral blood vessels, and thus to help matching cerebral blood flow to cerebral activity [106]. Indeed, in vivo and in vitro models of neurovascular coupling suggest an increase in intracellular calcium in the astrocytic endfeet as a consequence of metabotropic glutamate receptor stimulation during synaptic transmission [110$112]$. This finally results in a slow-developing vascular response, which could be either vasodilatory or vasoconstrictive. The significance of these responses needs however further evaluation [106]. In this context, products of the COX-1 metabolism and lactate concentration have been proposed to link the intracellular calcium increase in astrocytes to vascular blood flow $[113,114]$.

Apart from controlling the transfer of molecules from blood to brain, the BBB plays an important role in the protection of brain tissue against pathogens as it also separates the immune system from the CNS. Only a reduced number of immune cells enter the CNS and antibodies, which are too large to pass the $\mathrm{BBB}$, are absent in the CNS, conferring an 'immunoprivileged' state. It has been shown by two-photon microscopy that recruitment of blood leukocytes to the injured brain parenchyma is delayed in contrast to the rapid response observed in the meninges $[115,116]$. The role of identifying and neutralizing foreign bodies is largely taken up by microglia, which constitute $20 \%$ of the total glial cell population within the CNS. These cells are continuously sensing the surrounding environment and are the first to respond to even minor pathological changes in the CNS, initiating and orchestrating a coordinated neuro-inflammatory response [117]. Once recognized, a foreign body is ingested by microglial cells, which then act as an antigen-presenting cell that activates $T$ cells and release a number of proinflammatory cytokines and proteases. Activation of microglia might involve GJIC because the expression of $\mathrm{Cx} 43$ is increased in these cells in vivo after mechanical wounds [118]. Microglial cells respond to parenchymal necrotic injury in a first acute phase of process movement followed by a slower phase of soma movement. In parallel, a polarized migration of astrocytes surrounding the injury site is observed. The proposed mechanisms involve a calcium gradient within the astrocyte network depend- 
ing on ATP release to the extracellular environment via Cx hemichannels [116]. In contrast with these observations, however, activation of microglia has been associated with reduced $\mathrm{Cx} 43$ expression in astrocytes, reduced GJIC and decreased astroglial membrane resting potential in an in vitro co-culture model $[119,120]$.

Pathological events such as ischemia, hemorrhage and meningitis lead to BBB disruption and an important inflammatory response. Focal ischemia follows transient or permanent flow reduction in the territory of a cerebral artery, for example after embolic or thrombotic vessel occlusion. Typically, the ischemic lesion is characterized by an infarcted core which is surrounded by the ischemic border zone' with metabolically active, but electrically silent, neurons [121]. Indeed, disruption of the blood flow in the brain causes considerable damage and death of neural cells. Reduced oxygen supply (either hypoxia or anoxia) triggers rapid depolarization of neurons, and greatly compromises their ability to maintain transmembrane ion gradients. This is manifested in sodium and calcium influx initiating glutamate release from neuronal terminals, thus further amplifying the vicious circle by inducing 'glutamate excito-neurotoxicity' [122, 123]. Another source of glutamate is the activated microglia itself that may release the neurotransmitter through Cx43-made hemichannels [124]. The first line of defense against glutamate excito-neurotoxicity is formed by the astrocyte network. Astrocytes capture the neurotransmitter, which may be diluted within the network via gap junctions, acting therefore as a sink for glutamate in the CNS $[123,125]$. Consistent with this hypothesis, inflammation following ischemia is indeed increased in mice lacking Cx43 in astrocytes [126]. Ischemia is associated with significant ATP release followed by a highly increased concentration of ADO in the extracellular fluid in the CNS. ADO exerts a neuroprotective effect by inhibiting glutamate release. In a culture model of cerebral microvascular ECs, the production of ADO has been associated with a transient increase in the expression and activity of CD73 [127]. CD73 is expressed by several cell types in the brain including BBB ECs [128]. In the context of brain ischemia, a possible link between CD73 and $\mathrm{Cx}$ expression has not been directly investigated. Nevertheless, it is interesting to note that increased ADO concentration leads to increased $\mathrm{Cx} 43$ expression and stimulates GJIC in pituitary folliculostellate cells [129]. Due to the close proximity between CD73-expressing BBB ECs and $\mathrm{Cx} 43$-expressing astrocytes, a hypothetical regulation of $\mathrm{Cx} 43$ by $\mathrm{CD} 73$ may contribute to the dilution of glutamate through the astrocyte network.
Astrocytes contain a high concentration of glutathione and ascorbate providing thus a protective mechanism against reactive oxygen species. In cases of severe injury, the role of astrocytes may turn from good to bad as they may become a source of glutamate. Depolarization of astrocytes together with increased extracellular sodium concentration can reverse the glutamate transporter, thus producing glutamate efflux $[123,130]$. Furthermore, hemichannels may be involved in the release of glutamate by astrocytes as they can be opened by conditions such as low extracellular calcium, acidosis or activation of $\mathrm{P}_{2} \mathrm{X}_{7}$ receptors by high concentrations of extracellular ATP, conditions which are typically associated with ischemia $[123,131]$. Finally, GJIC of death signals between astrocytes may further contribute to the deleterious outcome after brain ischemia together with rapid depolarization (spreading depression), which determine the infarct size $[123,132]$.

\section{Concluding Remarks}

Within the vascular tree, Cxs play key roles in vascular pathophysiology. They also have a large, many-sided impact on disease development. In particular, the cross talk between the injured tissue and the vasculature, including adhesion and transmigration of inflammatory cells, is a key element of the inflammatory response. In large vessels such as the aorta, Cxs contribute to the chronic inflammatory response in the development of atherosclerosis. They show a dynamic expression pattern in atherogenesis and interfere in different steps of atherosclerotic plaque development. Thus, Cx37-made hemichannels in monocytes contribute to their adhesion and transmigration process across the endothelium. Endothelial Cx40 is implied in transmitting an anti-adhesive and thus antiinflammatory signal within the vascular endothelium. Often there is a balance between pro- and anti-inflammatory signaling pathways: in acute lung inflammation, Cx43 contributes to the spread of pro-inflammatory calcium waves within the lung capillary bed, leading to the expression of surface adhesion molecules for leukocytes. Contrary to this, recent data revealed that endothelial Cx40 delays the initiation of acute lung inflammation by promoting the intercellular exchange of ADO-evoked anti-inflammatory signaling along the vascular endothelium. Interestingly, Cx-specific signaling pathways can change importantly under inflammatory conditions: in the brain, astrocytic $\mathrm{Cx} 43$ is known to promote glucose transport from the vascular system to neurons and to 
help adapting the glucose supply to the actual needs of the tissue. Under pathological conditions such as focal ischemia and the subsequent massive release of glutamate, astrocytic $\mathrm{Cx} 43$ conveys the spread of pro-inflammatory calcium waves from the site of defect towards the intracerebral vasculature. Thus, Cxs confer many aspects of tissue homeostasis. Remarkably, CD73 represents a hither to unrecognized link between the communication pathways of hemichannels and gap junction channels, which may have profound consequences on the regulation of calcium signaling in inflamed tissues. Indeed, regulation of CD73 by GJIC may modulate the extracellular ATP/ADO ratio, and therefore influence the signaling pathways generated in target cells. Further research may reveal possibilities to influence the balance between pro- and anti-inflammatory signaling in the different sections of the vasculature to obtain beneficial effects on the outcome of diseases.

\section{Acknowledgments}

The authors like to thank Esther Sutter, Kim Chanson and Krystyna Pietrzak for excellent technical help. We would like to thank Davide Losa for helpful discussion. This work was supported by grants from the Swiss National Science Foundation (PPOOA-116897 and 310030-127551 to B.R.K. and 310000-119739 to M.C.) and Vaincre la Mucoviscidose (M.C.). K.E.L.S. was supported by the Schmidheiny Foundation, the Novartis Consumer Health Foundation and a grant-in-aid (Mimosa) from the Department of Pediatrics.

\section{References}

>1 Sàez JC, Berthoud VM, Brãnes MC, Martinez AD, Bayer EC: Plasma membrane channels formed by connexins: their regulation and functions. Physiol Rev 2003;83:13591400 .

$\checkmark 2$ Harris AL: Emerging issues of connexin channels: biophysics fills the gap. Q Rev Biophys 2001;34:325-472.

>3 Spray DC, Ye ZC, Ranson BR: Functional connexin 'hemichannels': a critical appraisal. Glia 2006;54:758-773.

4 Goldberg GS, Lampe PD, Nicholson BJ: Selective transfer of endogenous metabolites through gap junctions composed of different connexins. Nat Cell Biol 1999;1:457-459.

5 Kanaporis G, Mese G, Valiuniene L, White TW, Brink PR, Valiunas V: Gap junction channels exhibit connexin-specific permeability to cyclic nucleotides. J Gen Physiol 2008;131:293-305.

6 Willecke K, Eiberger J, Degen J, Eckhadt D, Roumualdi A, Güldenagel M, Deutsch U, Söhl G: Structural and functional diversity of connexin genes in the mouse and human genome. Biol Chem 2002;383:725-737.

$\checkmark 7$ Laird DW: Life cycle of connexins in health and disease. Biochem J 2006;394:527-543

$\checkmark 8$ De Maio A, Vega VL, Contreras JE: Gap junctions, homeostasis, and injury. J Cell Physiol 2002;191:269-282.

$\checkmark 9$ Chanson M, Derouette JP, Roth I, Foglia B, Scerri I, Dudez T, Kwak BR: Gap junctional communication in tissue inflammation and repair. Biochim Biophys Acta 2005;1711: 197-207.

-10 Haefliger JA, Nicod P, Meda P: Contribution of connnexins to the function of the vascular wall. Cardiovasc Res 2004;62:345-356.
1 de Wit C, Hoepfl B, Wolfle SE: Endothelial mediators and communication through vascular gap junctions. Biol Chem 2006;387:3-9.

12 Figueroa XF, Duling BR: Gap junctions in the control of vascular function. Antioxid Redox Signal 2009;11:251-266.

13 Brisset AC, Isakson BE, Kwak BR: Connexins in vascular physiology and pathology. Antioxid Redox Signal 2009;11:267-282.

$>14$ Figueroa XF, Isakson BE, Duling BR: Vascular gap junctions in hypertension. Hypertension 2006;48:804-811.

15 de Wit C, Boettcher M, Schmidt VJ: Signaling across the myoendothelial gap junctions - fact or fiction? Cell Commun Adhes 2008; 15:231-245.

$\checkmark 16$ Sandow SL, Haddock RE, Hill CE, Chadha PS, Kerr PM, Welsh DG, Plane F: What's, where and why at a vascular myoendothelial microdomain signalling complex. Clin Exp Pharmacol Physiol 2009;36:67-76.

17 Gabriels JE, Paul DL: Connexin43 is highly localized to sites of disturbed flow in rat aortic endothelium but connexin37 and connexin40 are more uniformly distributed Circ Res 1998;83:636-643.

18 Oviedo-Orta E, Errington RJ, Evans WH: Gap junction intercellular communication during lymphocyte transendothelial migration. Cell Biol Int 2002;26:253-263.

19 Zahler S, Hoffmann A, Gloe T, Pohl U: Gap junctional coupling between neutrophils and endothelial cells: a novel modulator of transendothelial migration. J Leukoc Biol 2003;73:118-126.

20 Eugenin EA, Branes MC, Berman JW, Sáez JC: TNF-alpha plus IFN-gamma induce connexin43 expression and formation of gap junctions between human monocytes/macrophages that enhance physiological responses. J Immunol 2003;170:1320-1328.
21 Scerri I, Tabary O, Dudez T, Jacquot J, Foglia B, Suter S, Chanson M: Gap junctional communication does not contribute to the interaction between neutrophils and airway epithelial cells. Cell Commun Adhes 2006;13: $1-12$.

22 Glass CK, Witztum JL: Atherosclerosis: the road ahead. Cell 2001;104:503-516.

$>23$ Libby P: Inflammation in atherosclerosis. Nature 2002;420:868-874.

$>24$ Hansson GK: Inflammation, atherosclerosis and coronary artery disease. N Engl J Med 2005;352:1685-1695.

25 Tedgui A, Mallat Z: Cytokines in atherosclerosis: pathogenic and regulatory pathways. Physiol Rev 2006;86:515-581.

26 Weber C, Zernecke A, Libby P: The multifaceted contributions of leukocyte subsets to atherosclerosis: lessons from mouse models. Nat Rev Immunol 2008;8:802-815.

$\checkmark 27$ Ross R: Cell biology of atherosclerosis. Annu Rev Physiol 1995;57:791-804.

28 Burke AP, Virmani R: Pathophysiology of acute myocardial infarction. Med Clin North Am 2007;91:553-572.

-29 Burnier L, Fontana P, Angelillo-Scherrer A, Kwak BR: Intercellular communication in atherosclerosis. Physiology (Bethesda) 2009; 24:36-44.

>30 Kwak BR, Mulhaupt F, Veillard N, Gros DB, Mach F: Altered pattern of vascular connexin expression in atherosclerosic plaques. Arterioscler Thromb Vasc Biol 2002;22:225230.

>31 Yeh HI, Lu CS, Wu YJ, Chen CC, Hong RC, Ko YS, Shiao MS, Severs NJ, Tsai CH: Reduced expression of endothelial connexin 37 and connexin 40 in hyperlipidemic mice: recovery of connexin 37 after 7-day simvastatin treatment. Arterioscler Thromb Vasc Biol 2003;23:1391-1397. 
-32 Isakson BE, Kronke G, Kadl A, Leitinger N, Duling BR: Oxidized phospholipids alter vascular connexin expression, phosphorylation, and heterocellular communication. Arterioscler Thromb Vasc Biol 2006;26:22162221.

$\checkmark 33$ Wong CW, Christen T, Roth I, Chadjichristos CE, Derouette JP, Foglia BF, Chanson M, Goodenough DA, Kwak BR: Connexin 37 protects against atherosclerosis by regulating monocyte adhesion. Nat Med 2006;12: 950-954.

34 Evans WH, De Vuyst E, Leybaert L: The gap junction cellular internet: connexin hemichannels enter the signalling limelight. Biochem J 2006;397:1-14.

35 Derouette JP, Desplantez T, Wong CW, Roth I, Kwak BR, Weingart R: Functional differences between human $\mathrm{Cx} 37$ polymorphic hemichannels. J Mol Cell Cardiol 2009;46: 499-507.

\36 Derouette JP, Wong C, Burnier L, Morel S, Sutter E, Galan K, Brisset AC, Roth I, Chadjichristos CE, Kwak BR: Molecular role of Cx37 in advanced atherosclerosis: a microarray study. Atherosclerosis 2009;206:69-76.

>37 Hou CJ, Tsai CH, Yeh HI: Endothelial connexins are down-regulated by atherogenic factors. Front Biosci 2008;13:3549-3557.

- 38 Yeh HI, Chang HM, Lu WW, Lee YN, Ko YS, Severs NJ, Tsai CH: Age-related alteration of gap junction distribution and connexin expression in rat aortic endothelium. J Histochem Cytochem 2000;48:1377-1389.

>39 de Wit C, Ross F, Bolz SS, Kirchhoff S, Kruger O, Willecke K, Pohl U: Impaired conduction of vasodilation along arterioles in connexin40-deficient mice. Circ Res 2000;86: 649-655.

40 Krattinger N, Capponi A, Mazzolai L, Aubert JF, Caille D, Nicod P, Waeber G, Meda P, Haefliger JA: Connexin40 regulates renin production and blood pressure. Kidney Int 2007;72:814-822.

$\checkmark 41$ Wagner C, de Witt C, Kurtz L, Grunberger C, Kurtz A, Schweda F: Connexin 40 is essential for the pressure control of renin synthesis and secretion. Circ Res 2007;100:556563.

42 Firouzi M, Kok B, Spiering W, Busjahn A, Bezzina CR, Ruijter JM, Koeleman BP, Schipper M, Groenewegen WA, Jongsma HJ, de Leeuw PW: Polymorphisms in human connexin40 gene promoter are associated with increased risk of hypertension in men. J Hypertens 2006;24:325-330.

43 Chadjichristos CE, Scheckenbach KE, van Veen TA, Richani Sarieddine MZ, de Wit C, Yang Z, Roth I, Bacchetta M, Viswambharan H, Foglia B, Dudez T, van Kempen MJ, Coenjaerts FE, Miquerol L, Deutsch U, Jongsma HJ, Chanson M, Kwak BR: Endothelial-specific deletion of connexin 40 promotes atherosclerosis by increasing CD73-dependent leukocyte adhesion. Circulation 2010;121: 123-131.
44 Zernecke A, Bidzhekov K, Ozüyaman B, Fraemohs L, Liehn EA, Luscher-Frizlaff JM, Luscher B, Schrader J, Weber C: CD73/ecto5 -nucleotidase protects against vascular inflammation and neointima formation. Cir culation 2006;113:2120-2127.

45 Lennon PF, Taylor CT, Stahl GL, Colgan SP: Neutrophil-derived 5'-adenosine monophosphate promotes endothelial barrier function via CD73-mediated conversion to adenosine and endothelial A2B receptor activation. J Exp Med 1998;188:1433-1443.

46 Narravula S, Lennon PF, Mueller BU, Colgan CP: Regulation of endothelial CD73 by adenosine: paracrine pathway for enhanced endothelial barrier function. J Immunol 2000; 165:5262-5268.

47 Koszalka P, Ozuyaman B, Huo Y, Zernecke A, Flogel U, Braun N, Buchheiser A, Decking UK, Smith ML, Sévigny J, Fear A, Weber AA, Molojavyi A, Ding Z, Weber C, Ley K, Zimmermann H, Gödecke A, Schrader J: Targeted disruption of CD73/ecto-5'-nucleotidase alters thromboregulation and augments vascular inflammatory response. Circ Res 2004; 95:814-821.

48 Blackburn JP, Peters NS, Yeh HI, Rothery S, Green CR, Severs NJ: Upregulation of connexin43 gap junctions during early stages of human coronary atherosclerosis. Arterioscler Thromb Vasc Biol 1995;15:1219-1228.

49 Polacek D, Bech F, McKinsey, Davies PF: Connexin43 gene expression in the rabbit arterial wall: effects of hypercholesterolemia, balloon injury and their combination. J Vasc Res 1996;34:19-30.

50 Kwak BR, Veillard N, Pelli G, Mulhaupt F, James RW, Chanson M, Mach F: Reduced connexin43 expression inhibits atherosclerotic lesion formation in low-density lipoprotein receptor-deficient mice. Circulation 2003;107:1033-1039.

51 Wong CW, Burger F, Pelli G, Mach F, Kwak BR: Dual benefit of reduced $\mathrm{Cx} 43$ on atherosclerosis in LDL receptor-deficient mice. Cell Commun Adhes 2003;10:395-400.

52 Boitano S, Safdar Z, Welsh DG, Bhattacharya J, Koval M: Cell-cell interactions in regulating lung function. Am J Physiol Lung Cell Mol Physiol 2004;287:L455-L459.

53 Foglia B, Scerri I, Dudez T, Chanson M: The role of connexins in the respiratory epithelium; in Harris A, Locke D (eds): Connexin: A Guide. Totowa, Humana Press, 2009, pp 359-370

54 Johnson LN, Koval M: Cross-talk between pulmonary injury, oxidant stress and gap junctional communication. Antioxid Redox Signal 2009; 11:355-367.

55 Lansley AB, Sanderson MJ, Dirksen ER: Control of the beat cycle of respiratory tract cilia by $\mathrm{Ca}^{2+}$ and cAMP. Am J Physiol 1992; 263:L232-L242.

56 Boitano S, Dirksen ER, Sanderson MJ: Intercellular propagation of calcium waves mediated by inositol trisphosphate. Science 1992 . 258:292-295.
57 Boitano S, Dirksen ER, Evans WH: Sequencespecific antibodies to connexins block intercellular calcium signaling through gap junctions. Cell Calcium 1998;23:1-9.

58 Martin FJ, Prince AS: TLR2 regulates gap junction intercellular communication in airway cells. J Immunol 2008;180:4986-4993.

59 Abraham V, Chou ML, George P, Pooler P, Zaman A, Savani RC, Koval M: Heterocellular gap junctional communication between alveolar epithelial cells. Am J Physiol Lung Cell Mol Physiol 2001;280:L1085L1093.

60 Guo Y, Martinez-Williams C, Yellowley CE, Donahue HJ, Rannels DE: Connexin expression by alveolar epithelial cells is regulated by extracellular matrix. Am J Physiol Lung Cell Mol Physiol 2001;280:L191-L202.

61 Ichimura H, Parthasarathi K, Lindert J, Bhattacharya J: Lung surfactant secretion by interalveolar $\mathrm{Ca} 2+$ signaling. Am J Physiol Lung Cell Mol Physiol 2006;291: L596-L601.

62 Isakson BE, Seedorf GJ, Lubman RL, Evans WH, Boitano S: Cell-cell communication in heterocellular cultures of alveolar epithelial cells. Am J Respir Cell Mol Biol 2003;29:552561.

63 Patel AS, Reigada D, Mitchell CH, Gates SR, Marguies SS, Koval M: Paracrine stimulation of surfactant secretion by extracellular ATP in response to mechanical deformation. Am J Physiol Lung Cell Mol Physiol 2005; 289:L489-L496.

64 Ashino Y, Ying X, Dobbs LG, Battacharya J: $\left[\mathrm{Ca}^{2+}\right]_{\mathrm{i}}$ oscillation regulate type II cell exocytosis in the pulmonary alveolus. Am J Physiol Lung Cell Mol Physiol 2000;279:L5-L13.

65 Isakson BE, Evans WH, Boitano S: Intercellular $\mathrm{Ca} 2+$ signaling in alveolar epithelial cells through gap junctions and by extracellular ATP. Am J Physiol Lung Cell Mol Physiol 2001;280:L221-L228.

66 Homolya L, Steinberg TH, Boucher RC: Cell to cell communication in response to mechanical stress via bilateral release of ATP and UTP in polarized epithelia. J Cell Biol 2000;150:1349-1360.

67 Ransford GA, Fregien N, Qiu F, Dahl G, Conner GE, Salathe M: Pannexin 1 contributes to ATP release in airway epithelia. Am J Respir Cell Mol Biol 2009;41:525-534.

68 Wiszniewski L, Sanz J, Scerri I, Gasparotto E, Dudez T, lacroix JS, Suter S, Gallati S, Chanson M: Functional expression of connexin30 and connexin 31 in the polarized human airway epithelium. Differentiation 2007;75:382-392.

-69 Chanson M, Berclaz PY, Dudez T, Scerri I, Wernke-Dollries K, Pizurki L, Pavirani A, Fiedler M, Suter S: Regulation of gap junctional communication by a pro-inflammatory cytokine in cystic fibrosis transmembrane conductance regulator-expressing but not cystic fibrosis airway cells. Am J Pathol 2001; 158:1775-1784 
70 Huang S, Dudez T, Scerri I, Thomas MA, Giepmans BNG, Suter S, Chanson M: Defective activation of c-Src in CF airway epithelial cells results in loss of TNF- $\alpha$-induced gap junction regulation. J Biol Chem 2003; 278:8326-8332.

71 Huang S, Jornot L, Wiszniewski L, Rochat T, Suter S, Lacroix JS, Chanson M: Src signaling links mediators of inflammation to $\mathrm{Cx} 43$ gap junction channels in primary and transformed CFTR-expressing airway epithelial cells. Cell Commun Adhes 2003;10:279-285.

72 Dudez T, Borot F, Huang S, Kwak BR, Baccheta $\mathrm{M}$, Ollero $\mathrm{M}$, Stanton BA, Chanson $\mathrm{M}$ : CFTR in a lipid raft-TNFR1 complex modulates gap junctional intercellular communication and IL- 8 secretion. Biochim Biophys Acta 2008;1783:779-788.

73 Park SJ, Lee KS, Kim SR, Min KH, Lee KY, Choe YH, Park SY, Hong SH, Lee YC: Change of connexin 37 in allergen-induced airway inflammation. Exp Mol Med 2007;39:629640.

74 MacCallum NS, Evans TW: Epidemiology of acute lung injury. Curr Opin Crit Care 2005; 11:43-49.

75 Ware LB, Matthay MA: The acute respiratory distress syndrome. N Engl J Med 2000; 342:1334-1349.

76 Xing X, Minamiya Y, Fu C, Bhattachaya J: $\mathrm{Ca}^{2+}$ waves in lung capillary endothelium. Circ Res 1996;79:898-908.

-77 Parthasarathi K, Ichimura H, Monma E, Lindert J, Quadri S, Issekutz A, Bhattacharya $\mathrm{J}$ : Connexin 43 mediates spread of $\mathrm{Ca}^{2+}$-dependent proinflammatory responses in lung capillaries. J Clin Invest 2006;116:2193 2220.

-78 Sarieddine MZ, Scheckenbach KL, Foglia B, Maass K, Garcia I, Kwak BR, Chanson M: Connexin43 modulates neutrophil recruitment to the lung. J Cell Mol Med 2009;13: 4560-4570.

79 Moreno AP, Chanson M, Anumonwo J, Scerri I, Seven HG, Taffet M, Delmar M: Role of the carboxyl terminal of connexin43 in transjunctional fast voltage gating. Circ Res 2002;90:450-457.

-80 Maass K, Chase SE, Lin X, Delmar M: Cx43 CT domain influences infarct size and susceptibility to ventricular tachyarrhythmias in acute myocardial infarction. Cardiovasc Res 2009;84:361-367.

-81 Schalper KA, Orellana JA, Berthoud VM, Sáez JC: Dysfunctions of the diffusional membrane pathways mediated by hemichannels in inherited and acquired human diseases. Curr Vasc Pharmacol 2009;7:486505 .

82 Rignault S, Haefliger JA, Waeber B, Liaudet L, Feihl F: Acute inflammation decreases the expression of connexin 40 in mouse lung. Shock 2007;28:78-85.
Zhang J, Wang W, Sun J, Li Q, Liu J, Zhu H, Chen T, Wang H, Yu S, Sun G, Chen W, Yi D: Gap junction channel modulates pulmonary vascular permeability through calcium in acute lung injury: an experimental study. Respiration 2010;80:236-245.

84 Eltzschig HK, Macmanus CF, Colgan SP: Neutrophils as sources of extracellular nucleotides: functional consequences at the vascular interface. Trends Cardiovasc Med 2008;18:103-107.

85 Thomson LF, Eltzschig HK, Ibla JC, Van de Wiele CJ, Resta R, Morote-Garcia JC, Colgan SP: Crucial role for ecto-5'-nucleotidase (CD73) in vascular leakage during hypoxia. J Exp Med 2004;200:1395-1405.

86 Völmer JB, Thomson LF, Blackburn MR: Ecto-5'-nucleotidase (CD73)-mediated adenosine production is tissue protective in a model of bleomycin-induced lung injury. J Immunol 2006;6:4449-4458.

87 Eckle T, Füllbier L, Wehrmann M, Khoury K, Mittelbronn M, Ibla J, Rosenberger P, Eltzschig HK: Identification of ectonucleotidases CD39 and CD73 in innate protection during acute lung injury. J Immunol 2007; 178:8127-8137.

88 Fernandez-Cobo M, Gingalewski C, Maio $\mathrm{AD}$ : Expression of the connexin 43 gene is increased in the kidneys and the lungs of rats injected with bacterial lipopolysaccharide. Shock 1998;10:97-102.

89 Di Stasi MR, Ley K: Opening the flood-gates: how neutrophil-endothelial interactions regulate permeability. Trends Immunol 2009;30:547-56

\$0 Eltzschig HK, Eckle T, Mager A, Küper N, Karcher C, Weissmüller T, Boengler K, Schulz R, Robson SC, Colgan SP: ATP release from activated neutrophils occurs via connexin 43 and modulates adenosine-dependent endothelial cell function. Circ Res 2006; 99:1100-1108.

91 Williams LR, Leggett RW: Reference values for resting blood flow to organs of man. Clin Phys Physiol Meas 1989;10:187-217.

$\checkmark 92$ Hossmann KA: Pathophysiology and therapy of experimental stroke. Cell Mol Neurobiol 2006;26:1057-1083.

93 Iadecola C: Neurovascular regulation in the normal brain and in Alzheimer's disease. Nat Rev Neurosci 2004;5:347-360.

-94 Feuerstein GZ, Liu T, Barone FC: Cytokines, inflammation, and brain injury: role of tumor necrosis factor-alpha. Cerebrovasc Brain Metab Rev 1994;6:341-360.

95 Tarkowski E, Rosengren L, Blomstrand C, Wikkelso C, Jensen C, Ekholm S, Tarkowski A: Intrathecal release of pro-and anti-inflammatory cytokines during stroke. Clin Exp Immunol 1997;110:492-499.

-96 Ballabh P, Braun A, Nedergaard M: The blood-brain barrier: an overview. Structure, regulation, and clinical implications. Neurobiol Dis 2004;16:1-13.
-97 Faraci FM, Heistad HH: Regulation of large cerebral arteries and cerebral microvascular pressure. Circ Res 1990;66:8-17.

$\checkmark 98$ Kuo I, Chan-Ling T, Wojcikiewicz R, Hill C: Limited intravascular coupling in the rodent brainstem and retina supports a role for glia in regional blood flow. J Comp Neurol 2008;511:773-787.

99 Segal SS: Regulation of blood flow in the microcirculation. Microcirculation 2005; 12:33-45.

100 Nagasawa K, Chiba H, Fujita H, Kojima T, Saito T, Endo T, Sawada N: Possible involvement of gap junctions in the barrier function of tight junctions of brain and lung endothelial cells. J Cell Physiol 2006;208: 123-132.

101 Theis M, Söhl G, Eiberger J, Willecke K: Emerging complexities in identity and function of glial connexins. Trends Neurosci 2005;28:188-195.

102 Grieb P, Foster RE, Strome D, Goodwin CW, Pape PC: $\mathrm{O}_{2}$ exchange between blood and brain tissues studied with ${ }^{18} \mathrm{O}_{2}$ indicator-dilution technique. J Appl Physiol 1985; 58:1929-1941.

103 Qutub AA, Hunt CA: Glucose transport to the brain: a systems model. Brain Res Brain Res Rev 2005;49:595-617.

104 Hawkins RA, O'Kane RL, Simpson IA, Vina JR: Structure of the blood-brain barrier and its role in the transport of amino acids. J Nutr 2006;136:218S-228S.

105 Bernacki J, Dobrowolska A, Nierwinska K, Malecki A: Physiology and pharmacological role of the blood-brain barrier. Pharmacol Rep 2008;60:600-622.

106 Iadecola C, Nedergaard M: Glial regulation of the cerebral microvasculature. Nat Neurosci 2007;10:1369-1376.

107 Blomstand F, Giaume C: Kinetics of endothelin-induced inhibition and glucose permeability of astrocyte gap junctions. J Neurosci Res 2006;83:996-1003.

108 Rouach N, Koulakoff A, Abudara V, Willecke K, Giaume C: Astroglial metabolic networks sustain hippocampal transmission. Science 2008;322:1551-1555.

109 Herrero-Gonzalez S, Valle-Casuso JC, Sanchez-Alvarez T, Giaume C, Medina JM, Tabanero A: Connexin43 is involved in the effect of endothelin-1 on astrocyte proliferation and glucose uptake. Glia 2009;57: 222-233.

-110 Zonta M, Angulo MC, Gobbo S, Rosengarten B, Hossmann KA, Pozzan T, Carmignoto G: Neuron-to-astrocyte signaling is central to the dynamic control of brain microcirculation. Nat Neurosci 2003;6:4350.

111 Wang X, Lou N, Xu Q, Tian GF, Peng WG, Han X, Kang J, Takano T, Nedergaard M: Astrocytic $\mathrm{Ca}^{2+}$ signaling evoked by sensory stimulation in vivo. Nat Neurosci 2006;9:816-823. 
112 Winship IR, Plaa N, Murphy TH: Rapid astrocyte calcium signals correlate with neuronal activity and onset of the hemodynamic response in vivo. J Neurosci 2007;27: 6268-6272.

- 113 Takano T, Tian GF, Peng W, Lou N, Libionka W, Han X, Nedergaard M: Astrocytemediated control of cerebral blood flow. Nat Neurosci 2006;9:260-267.

-114 Gordon GR, Choi HB, Rungta RL, Ellis-Davies GC, MacVicar BA: Brain metabolism dictates the polarity of astrocyte control over arterioles. Nature 2008;456:745-749.

115 Kim JV, Dustin ML: Innate response to focal necrotic injury inside the blood-brain barrier. J Immunol 2006;177:5269-5277.

116 Galea I, Bechmann I, Perry VH: What is immune privilege (not)? Trends Immunol 2007;28:12-18.

117 Tambuyzer BR, Ponsaerts P, Nouvwen EJ: Microglia: gatekeepers of central nervous system immunology. J Leukoc Biol 2009;85: 352-370.

-118 Eugenín EA, Eckardt D, Theis M, Willecke K, Bennett MV, Sáez JC: Microglia at brain stab wounds express connexin 43 and in vitro form functional gap junctions after treatment with interferon-gamma and tumor necrosis factor-alpha. Proc Natl Acad Sci USA 2001;98:4190-4195.
119 Faustmann PM, Haase CG, Romberg S, Hinkerohe D, Szlachta D, Smikalla D Krause D, Dermietzel R: Microglia activation influences dye coupling and $\mathrm{Cx} 43 \mathrm{ex}-$ pression of the astrocytic network. Glia 2003;4282:101-108.

120 Hikerohe D, Smikalla D, Haghikia A, Heupel K, Haase CG, Dermietzel R, Faustmann PM: Effects of cytokines on microglial phenotypes and astroglial coupling in an inflammatory co-culture model. Glia 2005; 52:85-97.

121 Astrup J, Siesjö BK, Symon L: Thresholds in cerebral ischemia. Stroke 1981;12:723-725.

122 Westbrook GL: Glutamate receptors and excitotoxicity. Res Publ Assoc Res Nerv Ment Dis 1993;71:35-50.

123 Giaume C, Kirchhoff F, Matute C, Reichenbach A, Verkhratsky A: Glia: the fulcrum of brain diseases. Cell Death Differ 2007;14: 1324-1335.

124 Takeuchi H, Jin S, Wang J, Zhang G, Kawanokuchi J, Kuno R, Sonobe Y, Mizuno T, Suzumura A: Tumor necrosis factor-alpha induces neurotoxicity via glutamate release from hemichannels of activated microglia in an autocrine manner. J Biol Chem 2006; 281:21362-21368.

125 Danbolt NC: Glutamate uptake. Prog Neurobiol 2001;65:1-105.

-126 Nakase T, Söhl G, Theis M, Willecke K, Naus CC: Increased apoptosis and inflammation after focal brain ischemia in mice lacking connexin43 in astrocytes. Am J Pathol 2004;164:2067-2075.
127 Li X, Zhou T, Zhi X, Zhao F, Yin L, Zhou P: Effect of hypoxia/reoxygenation on CD73 (ecto-5'-nucleotidase) in mouse microvessel endothelial cell lines. Microvasc Res 2006;72:48-53.

128 Zimmermann H: Biochemistry, localization and functional roles of ecto-nucleotidases in the nervous system. Prog Neurobiol 1996;49:589-618.

129 Lewis BM, Pexa A, Francis K, Verma V, McNicol AM, Scanlon M, Deussen A, Evans WH, Rees DA, Ham J: Adenosine stimulates connexin 43 expression and gap junctional communication in pituitary folliculostellate cells. FASEB J 2006;20:2585-2587.

130 Allen NJ, Karadottir R, Attwell D: Reversal or reduction of glutamate and GABA transport in CNS pathology and therapy. Pflugers Arch 2004;449:132-142.

131 Contreras JE, Sanchez HA, Veliz LP, Bukauskas FF, Bennett MV, Sáez JC: Role of connexin-based gap junction channels and hemichannels in ischemia-induced cell death in nervous tissue. Brain Res Brain Res Rev 2004;47:290-303.

132 Budd SL, Lipton SA: Calcium tsunamis: do astrocytes transmit cell death messages via gap junctions during ischemia. Nat Neurosci 1998;1:431-432. 